ABDI: Jurnal Pengabdian dan Pemberdayaan Masyarakat ISSN: 2656-369X (Print), 2684-8570 (Online)

Volume 3 No. 1, Juni 2021

http://abdi.ppj.unp.ac.id/index.php/abdi

Email: abdi@ppj.unp.ac.id

DOI: https://doi.org/10.24036/abdi.v3il.64

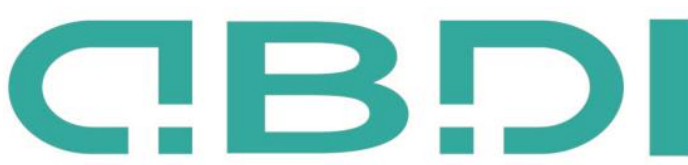

ABDI: JURNAL PENGABDIAN DAN PEMBERDAYAAN MASYARAKAT

\title{
Sosialisasi dan Pendesaianan Sistem Elektrokoagulasi Bertenaga Surya dalam Pengolahan Limbah Batik Cual
}

\author{
Sandi Sandi ${ }^{1}$, Andrian Saputra ${ }^{2}$, Deden Nurdandi ${ }^{3}$, Muhammad B. Hariyono ${ }^{4}$, \\ Redi Randika ${ }^{5}$, Yuant Tiandho ${ }^{6}$ \\ 1,2,3,4,5,6 Jurusan Fisika, Universitas Bangka Belitung \\ E-mail: sandiinsa14@gmail.com
}

\begin{abstract}
Abstrak
Perkembangan sektor pariwisata di Kep. Bangka Belitung diikuti oleh peningkatan permintaan produk budaya seperti batik cual. Meskipun dapat meningkatkan perekonomian, namun industri ini berpotensi menghasilkan limbah cair yang dapat mencemari lingkungan. Pada kegiatan pengabdian kepada masyarakat ini dilakukan sosialisasi dan pendesainan alat teknologi elektrokoagulasi bertenaga surya dalam pengolahan limbah batik cual. Agar dapat berjalan dengan baik maka kegiatan ini terdiri dari beberapa tahapan seperti koordinasi, pendesaian peralatan, evaluasi desain peralatan, finalisasi desain, kegiatan sosialisasi dan evaluasi kegiatan. Melalui koordinasi awal dengan mitra diperoleh informasi terkait produksi dan karakteristik limbah sebagai dasar pembuatan desain alat. Setelah dilakukan evaluasi diperoleh desain final alat untuk dipaparkan pada kegiatan sosialisasi. Kegiatan sosialisasi dihadiri oleh pemilik Kelompok Usaha Batik Melayu Pinang Sirih dan perwakilan dari Dinas Lingkungan Hidup Provinsi Kep. Bangka Belitung. Berdasarkan evaluasi yang dilakukan diketahui bahwa mitra dan perwakilan DLH Babel mengapresiasi desain yang diberikan.
\end{abstract}

Kata kunci: Batik cual; Elektrokoagulasi; Panel surya

\section{Abstract}

The development of the Bangka Belitung Islands' tourism sector was followed by an increase in demand for cultural products such as batik cual. Even though it can improve the economy, this industry can produce wastewater that can pollute the environment. In this community service activity, the socialization and design of a solar-powered electrocoagulation technology in the processing of batik cual wastewater was carried out. The activity consists of several stages, such as coordination, equipment design, evaluation of equipment design, finalizing the design, socialization activities, and evaluation of activities. Through initial coordination with partners, information regarding the production and characteristics of the waste can be obtained as a basis for making the designs. After the evaluation, the final design is obtained to be presented in the socialization activities. The socialization activity was attended by the Komunitas Usaha Batik Melayu Pinang Sirih and representatives from the Environmental Agency of the Province of Kep. Bangka Belitung. Based on the evaluation, it is known that the partners and representatives of DLH Babel appreciate the design given.

Keyword: Batik cual; Electrocoagulation; Solar panel

Received: 13 Oktober 2020

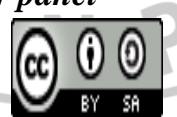


Sandi Sandi, Andrian Saputra, Deden Nurdandi, Muhammad B. Hariyono, Redi Randika, Yuant Tiandho Sosialisasi dan Pendesainan Sistem Elektrokoagulasi Bertenaga Surya dalam Pengolahan Limbah batik Cual

\section{Pendahuluan}

Semenjak sektor pertambangan timah mengalami penurunan produksi, Pemerintah Provinsi Kepulauan Bangka Belitung terus melakukan upaya pengembangan sektor pariwisata di provinsi ini. Selain untuk menghindari gejolak perekonomian yang mungkin muncul pasca era pertambangan, Kepulauan Bangka Belitung menyimpan berbagai destinasi wisata seperti pantai dan struktur geologi purba serta kebudayaan unik yang dibangun dari asimilasi Melayu dan Cina. Keunikan dan keindahan tersebut telah membawa Kepulauan Bangka Belitung menjadi salah satu destinasi wisata unggulan Indonesia (Badan Pusat Statistik Kepulauan Bangka Belitung, 2019).

Salah satu hasil kebudayaan masyarakat Bangka Belitung yang masih lestari dan kerap dipromosikan sebagai souvenir bagi para wisatawan adalah kain cual. Kain cual pertama kali dibuat di Kota Mentok pada tahun 1900 dalam wujud kain tenun. Tetapi karena harganya yang cukup tinggi maka pada beberapa tahun terakhir, para pelaku industri kreatif di provinsi ini mulai memperkenalkan cual dalam bentuk batik (Magdalena \& Santoso, 2019). Upaya pengembangan batik cual membuat produk ini makin diminati oleh wisatawan dan masyarakat Bangka Belitung.

Sejak tahun 2015, Kelurahan Selindung merupakan salah satu sentral produksi batik cual dalam bentuk industri rumahan. Salah satu kelompok usaha batik terbesar di kelurahan ini adalah Kelompok Usaha Batik Melayu Pinang Sirih. Kelompok batik cual ini telah memproduksi batik cual untuk berbagai keperluan seperti souvenir maupun seragam kantor/sekolah. Permasalahan utama yang dihadapi Kelompok Usaha Batik Melayu Pinang Sirih saat ini adalah belum adanya teknologi pengolahan air limbah batik cual. Dalam skala produksi yang masih relatif kecil seperti saat ini, mungkin hal tersebut belum berdampak secara signifikan. Namun seiring dengan tingginya permintaan produksi dan semakin berkembangnya usaha batik cual maka permasalahan tersebut harus dapat diselesaikan dengan baik. Hal ini dikarenakan dalam air limbah batik cual mengandung sisa pewarna dengan kadar tinggi sehingga berpotensi untuk mengganggu kehidupan biota dan bersifat karsinogenik (Suprihatin, 2014).

Pada penelitian yang telah dilakukan sebelumnya, diketahui bahwa teknologi elektrokoagulasi dapat memperbaiki kualitas limbah cair batik cual. Perbaikan kualitas meliputi aspek $\mathrm{pH}$, kejernihan, dan jumlah partikel terlarut (Sandi \& Tiandho, 2019). Oleh karena itu, berdasarkan masalah yang telah dipaparkan maka pada kegiatan ini ditawarkan solusi pengolahan limbah batik cual melalui penerapan teknologi elektrokoagulasi yang terintegrasi dengan panel surya. Adapun pada tahapan kali ini, tim pengabdian kepada masyarakat lebih menekankan pada tahapan sosialisasi dan pendesainan peralatan yang akan digunakan ketika mitra akan mengembangkan pabrik mini batik cual. Penggunaan panel surya bertujuan agar pengolahan limbah batik cual tidak menambah biaya produksi dan lebih ramah lingkungan. Hal ini didukung oleh data yang menyatakan bahwa Kep. Bangka Belitung memperoleh penyinaran matahari dengan potensi energi cukup besar mencapai sekitar 4,95 kWh/m² (Sandi \& Tiandho, 2019) (Handayani, Hulukati, \& Jaya, R., Tiandho, Y Abdullah, 2019) (Tiandho, 2019).

\section{Metode Pelaksanaan}

Pada masa pendemi Covid-19, seluruh kegiatan dalam pengabdian kepada masyarakat (PkM) ini dilaksanakan secara daring. Oleh karena itu, agar kegiatan PkM terkait sosialisasi dan pendesaianan peralatan teknologi elektrokoagulasi yang terintegrasi panel surya dalam pengolahan limbah batik cual di Kelompok Usaha Batik Melayu Pinang Sirih dapat berjalan dengan baik maka dilaksanakan beberapa tahapan kegiatan sebagai berikut: (1) Koordinasi dengan mitra; Kegiatan koordinasi awal ini bertujuan untuk memperoleh gambaran detail terkait dengan jumlah limbah yang dihasilkan beserta karakteristik fisik limbah yang dihasilkan. Hal ini dilakukan untuk mementukan spesifikasi desain peralatan. (2) Pendesainan peralatan teknologi elektrokoagulasi; Tahapan ini merupakan proses pendesaian awal sistem elektrokoagulasi berdasarkan deskripsi yang diberikan oleh mitra. Proses desain dilakukan dengan menggunakan software Pro Engineer Wildfire. (3) Meminta masukan dan evaluasi desain peralatan; Pada tahapan ini dilakukan evaluasi terkait desain yang telah dibuat berdasarkan masukan dari mitra. 
Proses masukan dilakukan secara daring menggunakan Google Forms dan Whatsapp. Hasil dari masukan yang diperoleh kemudian menjadi bahan pertimbangan untuk proses finalisasi desain peralatan elektrokoagulasi. (4) Finalisasi desain peralatan elektrokoagulasi dan pembuatan buku panduan; Tahapan ini merupakan proses pendesaian final sistem elektrokoagulasi berdasarkan deskripsi yang diberikan oleh mitra. Proses desain dilakukan dengan menggunakan software Sketchup agar desain yang dibuat lebih bersifat eye-catching. Selanjutnya, dilakukan pembuatan buku panduan pengoperasian peralatan untuk memberikan deskripsi yang lebih komprehensif ketika mitra akan mengembangkan peralatan yang telah didesain. (5) Melaksanakan sosialisasi; Kegiatan sosialisasi dilaksanakan secara daring menggunakan Zoom Meeting. Adapun peserta kegiatan sosialisasi adalah Pemilik Kelompok Usaha Batik Melayu Pinang Sirih dan Pihak Dinas Lingkungan Hidup Provinsi Kep. Bangka Belitung. Terlibatnya pihak Dinas Lingkungan Hidup bertujuan agar sistem yang didesain memperoleh masukan terkait standar baku mutu air limbah dan memberikan saran terkait proses pengajuan izin lingkungan sehingga mitra dapat memperoleh informasi secara utuh. (6) Evaluasi kegiatan; Program evaluasi kegiatan akhir dilakukan secara daring. Mitra diminta untuk mengisi berbagai pertanyaan yang berkaitan dengan pelaksanaan sosialisasi yang telah dilakukan beserta desain dan buku panduan yang telah dibuat.

\section{Hasil dan Pembahasan}

Melalui koordinasi dengan mitra Batik Melayu Pinang Sirih diperoleh informasi terkait potensi penerapan alat elektrokoagulasi. Selain itu, diperoleh juga gambaran kondisi jumlah limbah cair batik cual untuk setiap produksi. Diketahui bahwa dalam tiap produksi dihasilkan limbah cair sebanyak 20 liter. Oleh karena itu, desain daya tampung yang dihasilkan harus dapat menampung jumlah limbah cair tersebut. Adapun desain peralatan elektrokoagulasi yang akan disampaikan ke mitra berdasarkan informasi tersebut ditunjukkan oleh Gambar 1. Secara umum, teknologi pengolahan limbah batik cual yang didesain tersusun dari pengintegrasian beberapa peralatan seperti panel surya, charge controller, power supply, dan plat elektrokoagulasi.

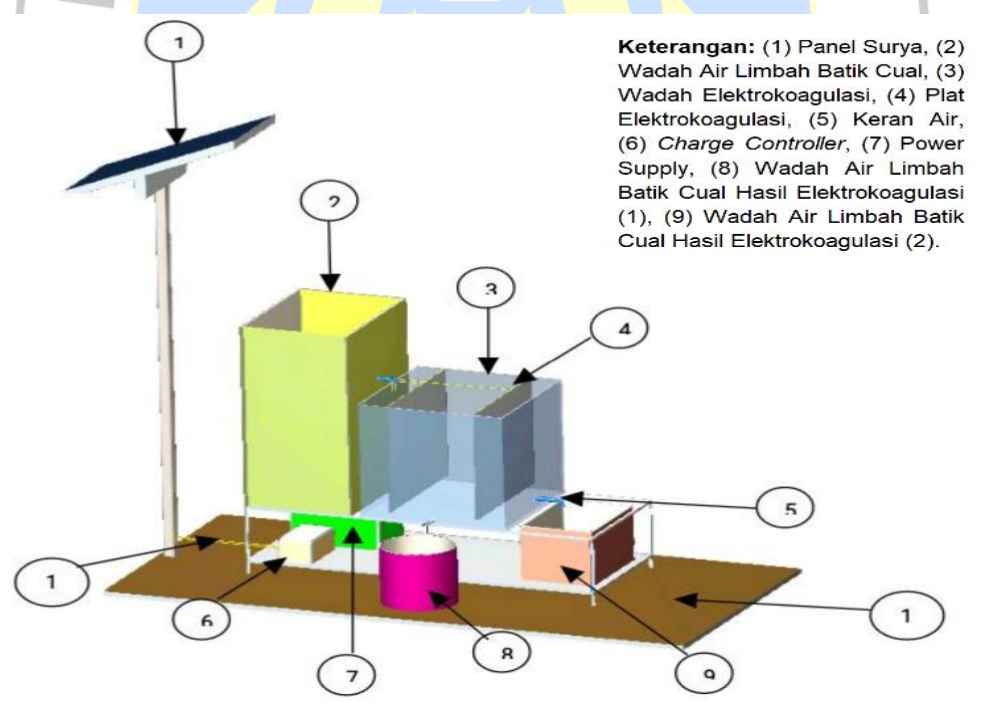

\section{Gambar 1. Desain Awal Teknologi Elektrokoagulasi}

Setelah desain teknologi elektrokoagulasi selesai dibuat maka desain tersebut kami sampaikan kepada mitra untuk meminta tanggapan dan saran untuk penyempurnaan. Menurut mitra, desain awal peralatan teknologi elektrokoagulasi pada Gambar 1 cenderung rumit karena berbagai peralatan terutama yang berkaitan dengan sistem kelistrikan berdiri secara masing-masing. Selain itu, desain pada Gambar 1 dirasa mitra kurang aman bagi anak-anak karena sistem kelistrikannya masih saling terpisah. Oleh karena itu, dibutuhkan suatu revisi desain yang melibatkan berbagai penyederhanaan sistem kelistrik sehingga diperoleh desain seperti Gambar 2. Pada Gambar 2 tampak bahwa sistem kelistrikan telah berada dalam satu sistem sehingga memudahkan proses penyimpanan dan instalasi. 
Sandi Sandi, Andrian Saputra, Deden Nurdandi, Muhammad B. Hariyono, Redi Randika, Yuant Tiandho Sosialisasi dan Pendesainan Sistem Elektrokoagulasi Bertenaga Surya dalam Pengolahan Limbah batik Cual

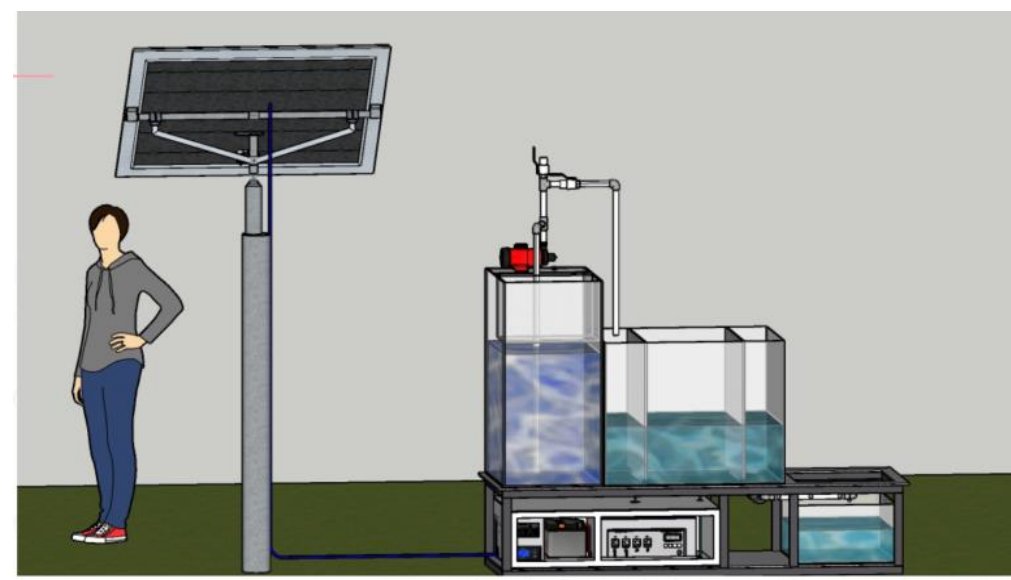

Gambar 2. Desain Final Teknologi Elektrokoagulasi
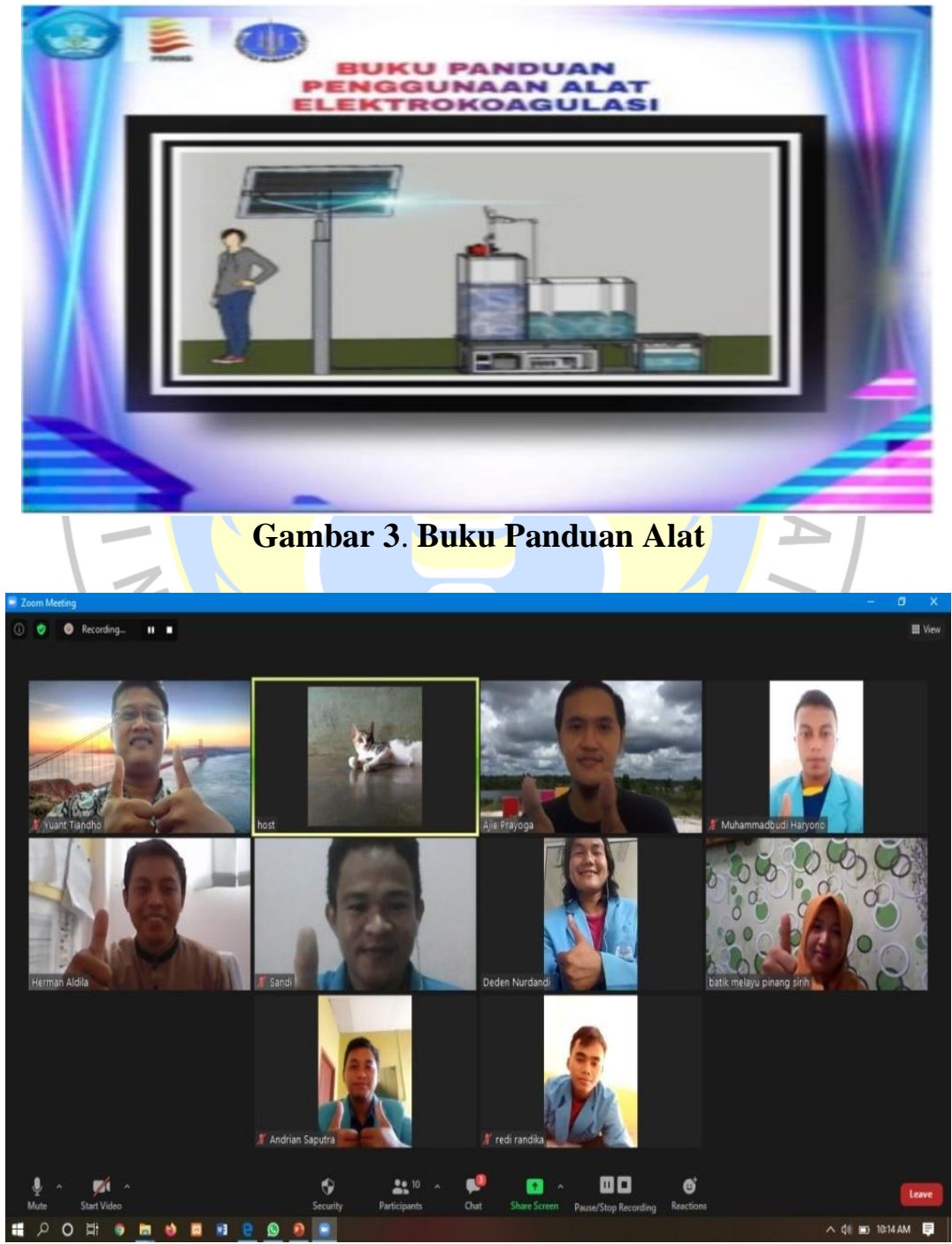

Gambar 4. Kegiatan Sosialisasi

Untuk memudahkan penggunaan, maka tim PkM juga menyusun suatu buku panduan penggunaan alat elektrokoagulasi seperti ditunjukkan pada Gambar 3. Buku panduan tersebut dapat digunakan untuk mempelajari proses instalasi, penggunaan, serta beberapa masalah yang mungkin muncul pada saat penggunaan alat. 
Sandi Sandi, Andrian Saputra, Deden Nurdandi, Muhammad B. Hariyono, Redi Randika, Yuant Tiandho Sosialisasi dan Pendesainan Sistem Elektrokoagulasi Bertenaga Surya dalam Pengolahan Limbah batik Cual

Pelaksanaan sosialisasi dilakukan menggunakan Zoom Meeting yang diselenggarakan pada 25 September tahun 2020. Kegiatan sosialisasi yang diikuti oleh Tim PKM-T dan dihadiri oleh Sekretaris Jurusan Fisika Universiats Bangka Belitung, Mitra Kelompok Usaha Batik Melayu Pinang Sirih, dan Dinas Lingkungan Hidup Provinsi Kep. Bangka Belitung seperti ditunjukkan pada Gambar 4. Kegiatan sosialisasi berisi tentang penjelasan penggunaan dan desain teknologi elektrokoagulasi serta tanggapan dan diskusi dengan mitra dan Dinas Lingkungan Hidup, Kep. Bangka Belitung.

Melalui kegiatan sosialisasi ini mitra berharap nantinya dapat berkolaborasi dengan tim PkM dalam pembuatan alat elektrokoagulasi yang nanti akan diaplikasikan dalam pabrik mini ketika Covid-19 berakhir. Selain itu, pihak pengelola Jurusan Fisika memberikan dukungannya dan berharap tim PkM dapat terus berinovasi dalam pengolahan air limbah batik cual. Dinas Lingkungan Hidup, Provinsi Kep. Bangka Belitung juga menuturkan hal yang serupa, ia mengapresiasi tim PkM bahwa teknologi yang sudah bagus ini harus terus dikembangkan dengan meningkatkan permanajemen limbah batik baik dari segi jumlah debit air yang dihasilkan serta lokasi pembuangan limbah yang telah diolah. Bahkan dalam penjelasan selanjutnya, Dinas Lingkungan Hidup Provinsi Kep. Bangka Belitung bersedia untuk membantu penerbitan izin lingkungan untuk pabrik batik cual apabila industri tersebut akan menggunakan peralatan yang didesain

Berdasarkan hasil evaluasi, diketahui bahwa mitra mengalami peningkatan pemahaman terkait karakteristik limbah batik cual yang diizinkan untuk dibuang ke lingkungan serta metode pengolahan limbah yang potensial untuk diaplikasikan. Dengan demikian, dapat dinyatakan bahwa pendesainan alat elektrokoagulasi untuk pengolahan limbah memiliki potensi aplikasi yang besar serta diharapkan dapat menjadikan Kelompok Usaha Batik Melayu Pinang Sirih menjadi komunitas usaha batik cual percontohan.

\section{Kesimpulan}

Meningkatnya jumlah permintaan dan produksi batik cual akan meningkatkan jumlah limbah yang dihasilkan. Karena mengandung zat pewarna seperti remazol yang pekat maka penganganan limbah cair batik dalam skala besar perlu diperhatikan. Teknologi elektrokoagulasi merupakan teknologi yang dapat digunakan untuk memperbaiki kualitas limbah cair batik cual. Penggunaanya yang terintegrasi dengan sel surya diharapkan dapat mereduksi biaya operasional alat ketika digunakan. Setelah melalui evaluasi, desain teknologi yang dilakukan pada kegiatan PkM ini telah sesuai dengan yang diharapkan mitra. Sehingga apabila pandemik Covid-19 telah berlalu dan mitra akan mengembangkan pabrik mini batik cual, maka mitra akan melanjutkan kerja sama terkait implementasi peralatan yang telah didesain. Setelah dilakukan sosialisasi terkait pengolahan limbah batik cual dengan elektrokoagulasi, mitra mengalami peningkatan pengetahuan tentang standar baku air limbah yang diizinkan untuk dibuang ke lingkungan. Selain itu, mitra juga telah cukup memahami beberapa metode pengolahan limbah batik cual terutama yang berkaitan dengan elektrkoagulasi.

\section{Daftar Pustaka}

Badan Pusat Statistik Kepulauan Bangka Belitung. (2019). Perkembangan Pariwisata dan Transportasi Kepulauan Bangka Belitung Oktober 2019. Bangka Belitung: BPS Bangka Belitung.

Handayani, T. P., Hulukati, S. A., \& Jaya, R., Tiandho, Y Abdullah, R. (2019). The prototype of solar-powered building lighting IoT. IOP Conference Series: Materials Science and Engineering. IOP.

Magdalena, H., \& Santoso, H. (2019). Strategi mengenali motif khas kain tenun cual bangka dengan AHP. Informatics Journal, 1(3), 96-112.

Sandi, D., \& Tiandho, Y. (2019). Pengaruh Jarak antar Plat dalam Penjernihan Batik Cual dengan Metode Elektrokoagulasi. Seminar Nasional Penelitian Dan Pengabdian Kepada Masyarakat Fakultas Teknik Universitas Bangka Belitung-2019 (SNPPM FT UBB-2019). Bangka Belitung: Universitas Bangka Belitung. 
Sandi Sandi, Andrian Saputra, Deden Nurdandi, Muhammad B. Hariyono, Redi Randika, Yuant Tiandho Sosialisasi dan Pendesainan Sistem Elektrokoagulasi Bertenaga Surya dalam Pengolahan Limbah batik Cual

Suprihatin, H. (2014). Kandungan Organik Limbah Cair Industri Batik Jetis Sidoarjo Dan Alternatif Pengolahannya. Riau: Pusat Penelitian Lingkungan Hidup Universitas Riau.

Tiandho, Y. (2019). Solar energy potential in Bangka Belitung Islands, Indonesia. IOP Conf. Series: Earth and Environmental Science.

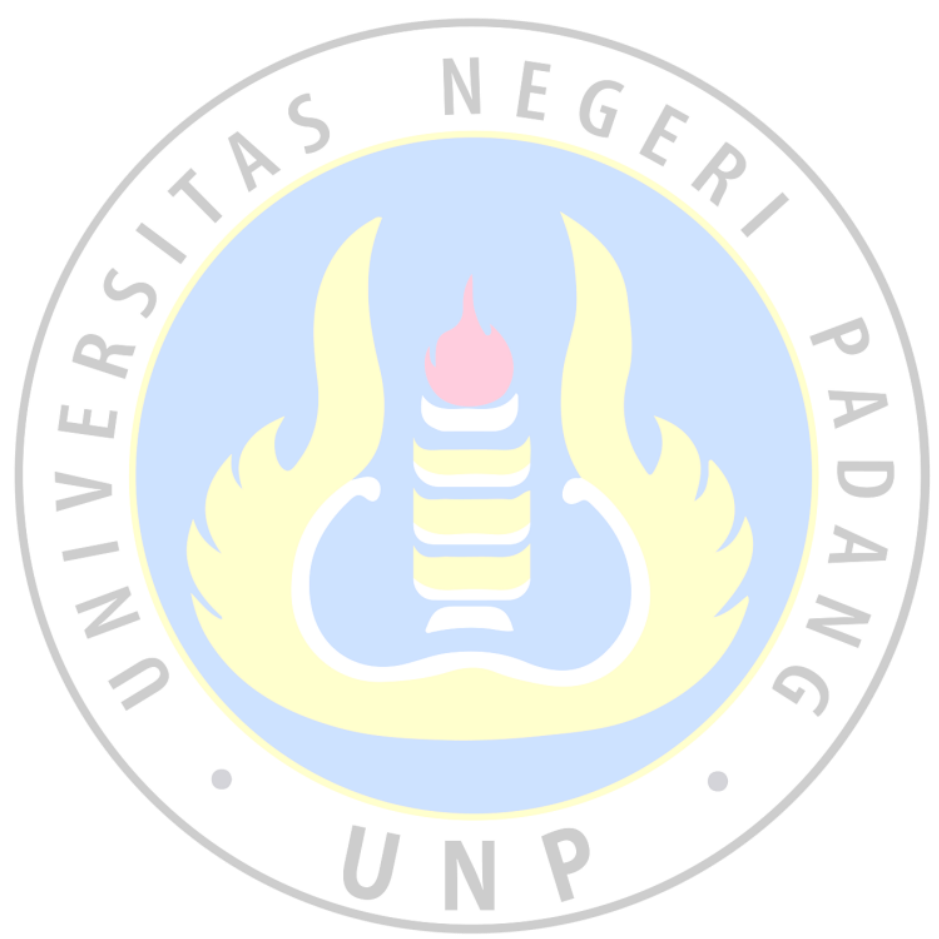

